T. Roose, A. Lekić, M. M. Alam and J. Beerten, "Stability Analysis of High-Frequency Interactions Between a Converter and HVDC Grid Resonances," in IEEE Transactions on Power Delivery, Early access.

Digital Object Identifier: 10.1109/TPWRD.2020.3041176

URL:

https://ieeexplore.ieee.org/document/9272858

(C) 2020 IEEE. Personal use of this material is permitted. Permission from IEEE must be obtained for all other uses, in any current or future media, including reprinting/republishing this material for advertising or promotional purposes, creating new collective works, for resale or redistribution to servers or lists, or reuse of any copyrighted component of this work in other works. 


\title{
Stability Analysis of High-Frequency Interactions Between a Converter and HVDC Grid Resonances
}

\author{
Thomas Roose (iD, Student Member, IEEE, Aleksandra Lekić (iD, Member, IEEE, Mohammad M. Alam (iD), \\ and Jef Beerten (D), Senior Member, IEEE
}

\begin{abstract}
This paper analyzes high-frequency interactions between a Modular Multilevel Converter (MMC) and High Voltage Direct Current (HVDC) grid resonances by studying their effect on the system stability. The recent appearance of converterrelated instabilities due to high-frequency oscillations at the converter's ac side raises concerns about whether similar interactions can also take place at its dc side. To determine the risks imposed by such interactions within an HVDC grid, this paper assesses the impact of the MMC internal dynamics and dc system resonances on the stability using an analytical impedance-based method. The effect of fault current-limiting inductors, grid topology changes and transmission line length is investigated, indicating that these parameters considerably influence the electromagnetic characteristics of the HVDC grid and consequently the system stability. Furthermore, a sensitivity analysis of the MMC internal controller dynamics on the converter's non-passivity, causing the instability, is performed.
\end{abstract}

Index Terms-DC resonances, HVDC grid, Impedance-based, Modular Multilevel Converter (MMC), Stability analysis

\section{INTRODUCTION}

$\mathbf{V}$ OLTAGE Source Converter (VSC) based High Voltage Direct Current (HVDC) is one of the key enabling technologies for massive integration of renewable energy sources in the electricity grid. HVDC systems are capable of high power transfer over long distances and interconnecting asynchronous areas [1]. Recently, the Modular Multilevel Converter (MMC) emerged as the preferred VSC-type due to its improved harmonic properties and low switching losses [2].

Converter-based systems in general, however, introduce fast dynamics that may have a negative influence on the system stability. In the past decades, converter-related instabilities occurred for instance in railway systems and offshore wind farms [3], [4]. More recently, several unstable ac-side interactions have been reported in VSC-HVDC systems, involving highfrequency grid resonances [5]-[8]. The root cause of these instability phenomena can be traced down to the interaction between the non-passive or negative resistive behavior of a converter in the small-signal sense and the electromagnetic

The work of T. Roose was funded by a research grant from the Research Foundation - Flanders (FWO) and VITO, Grant no. 1182519N. This work is part of the Neptune project, supported by the Energy Transition Fund, FOD Economy, Belgium. This work was supported by the FWO under Grant no. G0D2319N. The research of J. Beerten was funded by the FWO under Grant no. $12 \mathrm{D} 1117 \mathrm{~N}$.

T. Roose, A. Lekić and J. Beerten are with ELECTA, Department of Electrical Engineering, KU Leuven, Leuven 3000, Belgium, and also with EnergyVille, Genk 3600, Belgium (e-mail: thomas.roose@kuleuven.be, A.Lekic@tudelft.nl, jef.beerten@kuleuven.be)

M. M. Alam is with VITO, Mol 2400, Belgium and also with EnergyVille, Genk 3600, Belgium (e-mail: meraj.alam@vito.be) characteristics of the grid [9]. This type of negative interaction is nowadays commonly referred to as harmonic instability [10], [11] or electromagnetic instability [12].

Hitherto, the study of converter-grid interactions has been predominantly focusing on interactions with the ac grid. A stability analysis of grid-connected VSCs in a weak ac grid condition was performed in [13]. This study showed that a low-frequency unstable oscillation appearing in the system was related to the dynamics of the outer control. In [14], dynamic interactions above the fundamental frequency were analyzed in an ac network with high penetration of MMCs, indicating the risk of unstable interactions in the high-frequency range. In [15], the interaction between an MMC-based HVDC link and an offshore wind farm was studied, showing the importance of the onshore station and dc cable dynamics for analyzing the harmonic stability of the offshore ac system.

Due to the emergence of multi-terminal HVDC grids, the analysis of the dc-side stability in general is rising to prominence. In [16], an eigenvalue and participation factor analysis was performed to identify unstable modes in the Cigré dc grid test system, which were related to the outer control. In [17], an impedance-based modeling approach has been presented in order to investigate the stability of a VSC-HVDC link with two-level converters. It was demonstrated that the non-passivity of the two-level VSC admittance can interact with the dc network resonances, causing instability. However, a simplified pi-section model was used for representing the dc cables. An harmonic stability analysis of a back-to-back MMC-based HVDC system was recently presented in [18]. The analysis results demonstrate that the DC voltage controller of the MMC may degrade the system's damping and stability, causing unstable oscillation below the fundamental frequency. Based on an eigenvalue analysis and impedance-based analysis, similar results were obtained in [19] where the DC voltage controller was shown to adversely impacts the lower frequency dynamics of a cable-based MMC-based HVDC link. A method to investigate de network instabilities in multi-terminal HVDC systems with two-level VSCs has been presented in [20]. Unstable resonances below twice the fundamental frequency were identified. In [21], an impedance-based interaction and stability analysis of cable-based multi-terminal HVDC systems using the two-level VSC topology was performed, revealing unstable interactions below the fundamental frequency.

The stability analysis of previous studies, however, mainly focused on interactions in a relatively low frequency range where the converter dynamics are primarily dominated by the slower outer control loops. Consequently, the digital 
implementation of controllers and filters, which affects the converter's high-frequency dynamics [12], has typically been left unaddressed. In addition, the majority of the studies analyzed HVDC grids consisting of two-level VSCs instead of MMCs. Due to the specific internal dynamics of the MMC, e.g. the circulating current control, the results for two-level topologies cannot be generalized [22]. The extent to which MMC-based HVDC grids can potentially suffer from highfrequency interactions between converters and dc-side grid resonances, similar to reported ac-side problems, has thus so far not been addressed in literature.

This paper aims at filling the gap by (i) presenting an indepth assessment of the risk of high-frequency harmonic instability within MMC-based HVDC grids and by (ii) discussing the extent to which the problem is similar to or different from the high-frequency interactions observed at the ac-side of VSC-HVDC systems. A detailed study is performed to determine the impact of the MMC internal dynamics and HVDC grid resonances on the system stability. The dc-side stability of the MMC-based HVDC grid is analyzed through an analytical impedance-based method. The impedance-based representation of the $\mathrm{MMC}$ and $\mathrm{dc}$ transmission lines are obtained, allowing to perform the analysis on system-level by using the nodal admittance matrix. The influence of fault current-limiting inductors, grid topology changes and transmission line length on the stability of the MMC-based HVDC grid is investigated, as these parameters determine the HVDC grid characteristics. Furthermore, a sensitivity analysis of the MMC non-passivity as a function of its specific internal dynamics, i.e. circulating current control, output current control, aggregated time delays, and the type of outer control is performed. Finally, the stability analysis in the frequency domain is compared with time-domain simulations in the EMT-type software PSCAD to validate the results.

\section{MATHEMATICAL MODELING}

The high-frequency harmonic stability study of an MMCbased HVDC grid presented in this paper relies on an analytical impedance-based method [23]. The method studies converter-grid interactions by analyzing the loop-gain of the system closed-loop representation as depicted in Fig. 1 for a generic MMC-based HVDC grid which consists of multiple converters, dc cables or overhead lines and dc inductors $L_{d c}$ installed as part of the HVDC grid protection. The closedloop representation enables to determine the system stability by analyzing the Nyquist stability criterion according to the Nyquist plot of the loop-gain $L(s)$, which is defined as

$$
L(s)=Y_{M M C}(s) Z_{b u s}(s) .
$$

If the two subsystems $Y_{M M C}(s)$ and $Z_{b u s}(s)$ are stable, there are no open-loop poles in the right half plane and the stability of the closed-loop system is determined based on the encirclements of the Nyquist curve around the -1 point [24]. To obtain the loop-gain, the converter and HVDC grid dynamics need to be represented in terms of a small-signal MMC dc-side admittance $Y_{M M C}$ and small-signal equivalent network dc-side impedance $Z_{b u s}$, dependent on the dc voltage

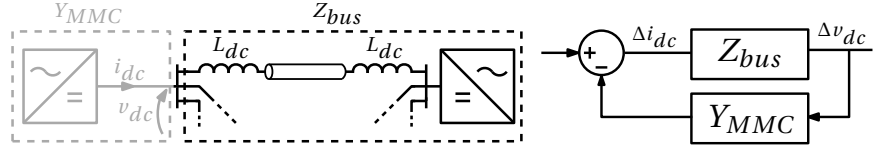

Fig. 1. Closed-loop representation of generic MMC-based HVDC grid with fault current-limiting inductors

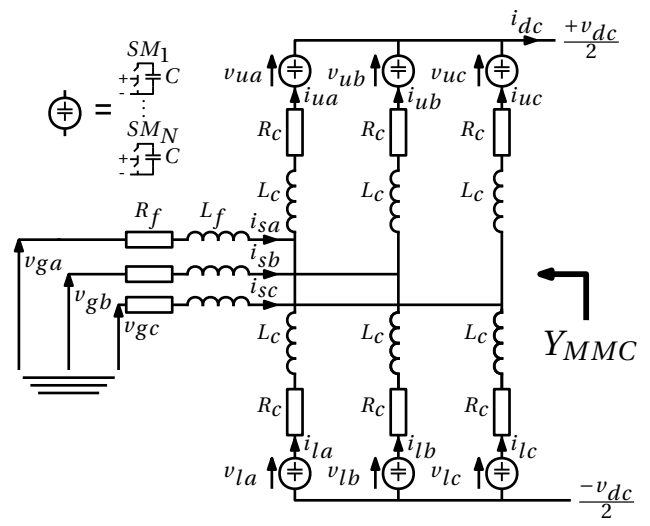

Fig. 2. Modular multilevel converter (MMC) topology

$v_{d c}$ and dc current $i_{d c}$. The expressions for $Y_{M M C}$ and $Z_{b u s}$ are derived in the next sections.

\section{A. MMC control structure and dc-side admittance}

The dynamic behavior of the MMC is mainly determined by its topology, depicted in Fig. 2, and converter control structure. The MMC control structure is a cascaded structure consisting of a faster inner control, depicted in Fig. 3, and a slower outer control as shown in Fig. 4.

According to Fig. 2, the MMC has $N$ half-bridge submodules (SM) per arm with each a capacitance value $C$. The arm inductance and resistance are given by $L_{c}$ and $R_{c}$ respectively, where the transformer is represented by its equivalent inductance $L_{f}$ and resistance $R_{f}$. The total inductance $L_{t}$ and resistance $R_{t}$ are then defined as

$$
L_{t}=L_{f}+\frac{L_{c}}{2} \quad \text { and } \quad R_{t}=R_{f}+\frac{R_{c}}{2} .
$$

The upper arm voltage and current, $v_{u}$ and $i_{u}$, and the lower arm voltage and current, $v_{l}$ and $i_{l}$, of the MMC contain a dc and fundamental frequency component. These are separated by defining the following variables,

$$
v_{s}=\frac{v_{l}-v_{u}}{2}, \quad i_{s}=i_{u}-i_{l} \quad \text { and } \quad i_{c}=\frac{i_{u}+i_{l}}{2}
$$

where $v_{s}$ and $i_{s}$ are the output voltage and current and $i_{c}$ the circulating current.

To control $i_{s}$ and $i_{c}$, two inner control loops are implemented, i.e. the output current control (OCC) and circulating current control (CCC), as shown in Fig. 3. The OCC controls the output current through a proportional-integral (PI) controller in the dq-frame where the phase-locked loop (PLL) provides the angle $\theta$ for the reference frame. The angle $\theta$ is determined by measuring the voltage at the point of common coupling (PCC), defined as $v_{g}$. The fundamental angular frequency is represented by $\omega_{1}$. The CCC suppresses the 


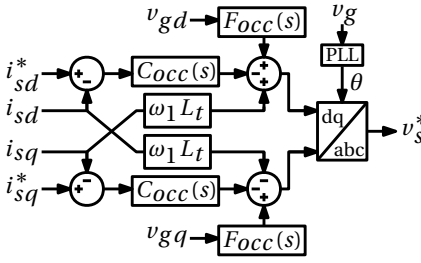

(a)

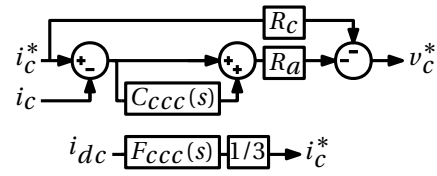

(b)
Fig. 3. MMC inner control loops: (a) Output current control (OCC); (b) Circulating current control (CCC).
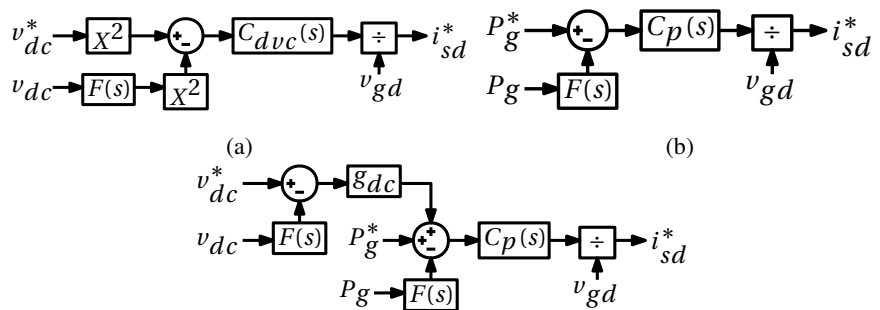

(c)

Fig. 4. MMC outer control loops: (a) DC voltage control (DVC); (b) Active power control (P); (c) Droop control.

additional $100 \mathrm{~Hz}$-component superposed on the dc value in the circulating current $i_{c}$ by a tuned proportional-resonant (PR) controller and tracks the circulating current reference $i_{c}^{*}$. If the circulating current is not controlled, it will negatively affect the charging and discharging of the submodule capacitors. The transfer functions $F(s), F_{o c c}(s)$ and $F_{c c c}(s)$ represent firstorder measurement filters. The OCC PI-controller and the CCC resonant part are defined as

$C_{o c c}(s)=K_{p, o c c}+\frac{K_{i, o c c}}{s}$, and $C_{c c c}(s)=\frac{K_{r, c c c} s}{s^{2}+\left(2 \omega_{1}\right)^{2}}$,

where $K_{p}$ is the proportional gain, $K_{i}$ the integral gain and $K_{r}$ the resonant gain. The proportional gain of the CCC is indicated with $R_{a}$. The outer control shown in Fig. 4 provides the reference value of the d-axis output current $i_{s d}^{*}$. In general, three types of outer control loops can be implemented for this, i.e. de voltage control (DVC), active power control (P) of PCC active power $P_{g}$ or droop control with droop constant $g_{d c}$. Given that the focus is on the dc side, no outer reactive power or ac voltage controller are considered in this paper. Hence, the reference value of the q-axis output current $i_{s q}^{*}=0$. The $\mathrm{PI}-$ controller of DVC and $\mathrm{P}$ are given by

$C_{d v c}(s)=K_{p, d v c}+\frac{K_{i, d v c}}{s}$, and $C_{p}(s)=K_{p, p}+\frac{K_{i, p}}{s}$.

Based on the output voltage reference $v_{s}^{*}$ and internal voltage reference $v_{c}^{*}$ provided by the inner control, the submodule switching signals are calculated through direct voltage control which determine the applied upper and lower arm voltage, $v_{u}$ and $v_{l}$. Between the calculated voltage references and the actual converter voltages, there is a time delay $D(s)$

$$
v_{s}(s)=D(s) v_{s}^{*}(s) \text { and } v_{c}(s)=D(s) v_{c}^{*}(s),
$$

which is primarily caused by the sampling circuit, analogdigital converter, calculation process in the digital signal processor, modulation and submodule balancing of the MMC [25]. The time delay $D(s)$ is defined as an exponential function $e^{-s T_{d}}$ with a duration of $T_{d}$. As the focus in this paper is put on the dc side, a strong ac grid is assumed providing a constant PCC voltage $v_{g}$. Consequently, the impact of the PLL on the MMC dc-side dynamics can be neglected in the dc-side stability analysis under this assumption [21].

The small-signal dc-side admittance of the MMC can now be obtained as in [26]

$$
Y_{M M C}(s)=\frac{-\Delta i_{d c}}{\Delta v_{d c}}=\frac{Y_{1}(s)}{Y_{2}(s)},
$$

where

$$
\begin{aligned}
Y_{1}(s)= & -\left(\frac{1}{2}+\frac{D(s) R_{c} i_{c, 0}}{v_{d c, 0}}\right)\left(\frac{N}{s C}\right)\left[\frac{i_{s, 0}^{d}}{v_{d c, 0}} K_{s 11}(s) M(s)\right. \\
& +\frac{v_{s, 0}^{d}}{v_{d c, 0}} G_{c c 11}(s) M(s)+\frac{i_{s, 0}^{q}}{v_{d c, 0}} K_{s 21}(s) M(s) \\
& \left.+\frac{v_{s, 0}^{q}}{v_{d c, 0}} G_{c c 21}(s) M(s)-\frac{P_{s, 0}}{v_{d c, 0}^{2}}+\frac{6 D(s) R_{c} i_{c, 0}^{2}}{v_{d c, 0}^{2}}\right] \\
& +\frac{6 D(s) R_{c} i_{c, 0}}{v_{d c, 0}}+3
\end{aligned}
$$

and

$$
\begin{aligned}
Y_{2}(s)= & 2 L_{c} s+2 R_{c}-\left(\frac{1}{2}+\frac{D(s) R_{c} i_{c, 0}}{v_{d c, 0}}\right)\left(\frac{N}{s C}\right) \\
& {\left[\frac{2 D(s) i_{c, 0}}{v_{d c, 0}}\left(R_{a}\left(1-F_{c c c}(s)\right)-R_{c}\left(1+F_{c c c}(s)\right)\right)\right.} \\
& \left.+\frac{2 R_{a} i_{c, 0}}{v_{d c, 0}} D(s) C_{c c c}(s)\left(1-F_{c c c}(s)\right)-1\right] \\
& -2 D(s) F_{c c c}(s)\left(R_{a}+R_{c}\right)+2 D(s) R_{a} \\
& +2 D(s) C_{c c c}(s) R_{a}\left(1-F_{c c c}(s)\right) .
\end{aligned}
$$

A negative sign is added to the dc current as $Y_{M M C}(s)$ is defined as an input admittance. Steady-state values in the expression of $Y_{M M C}(s)$ are indicated with 0 as subscript. The dc-side power is represented by $P_{s, 0}$. The matrix $\boldsymbol{G}_{c c}$ gives the relation between the dq-components of the output current and output current reference, where matrix $\boldsymbol{K}_{\boldsymbol{s}}$ gives the relation between the dq-components of the output voltage and output current reference. Vectors and matrices are noted in bold italic.

$$
\Delta i_{s}=G_{c c} \Delta i_{s}^{*} \text { and } \Delta v_{s}=K_{s} \Delta i_{s}^{*}
$$

where $\boldsymbol{G}_{\boldsymbol{c} \boldsymbol{c}}$ and $\boldsymbol{K}_{\boldsymbol{s}}$ are defined as

$$
\boldsymbol{K}_{\boldsymbol{s}}=\left[\begin{array}{cc}
-L_{t} s+R_{t} & \omega_{1} L_{t} \\
-\omega_{1} L_{t} & -L_{t} s+R_{t}
\end{array}\right] \underbrace{\frac{D(s) C_{o c c}(s)}{c}\left[\begin{array}{cc}
a & b \\
-b & a
\end{array}\right]}_{\boldsymbol{G}_{\boldsymbol{c c}}}
$$

The parameters $a, b$ and $c$ are equal to

$$
\begin{aligned}
& a=L_{t} s+R_{t}+D(s) C_{o c c}(s), \quad b=\omega_{1} L_{t}(1-D(s)) \\
& \text { and } c=a^{2}+b^{2} .
\end{aligned}
$$

The transfer function $M(s)$ in (8) represents the influence of the outer control on the dc-side dynamics of the MMC. How $M(s)$ and subsequently $Y_{M M C}(s)$ differ for the three types of outer controls is discussed more elaborately in Section III. 


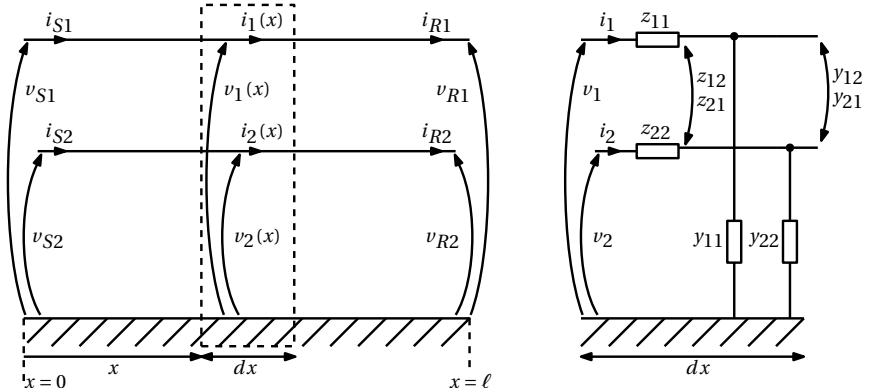

Fig. 5. General representation of a two-phase transmission line with a detail of an infinitesimal length $d x$

\section{B. DC transmission line modeling}

To analyze the high-frequency interactions with resonances in the HVDC grid, an accurate representation of the dc transmission lines is required which takes into account the frequency-dependency of the line parameters. Furthermore, it is important to include the mutual coupling between the dc poles in the case of dc overhead lines as it has a significant impact on the parameters at the higher frequency range [27]. Consequently, the frequency-dependent distributed line model is used. In contrast to a state-space representation, the impedance-based modeling approach can include nonrational functions, e.g. exponential functions, which allows to implement the full detailed analytical transmission line model.

The general representation of a two-phase transmission line is depicted in Fig. 5. According to the voltage and current drop across an infinitesimal length $d x$, the transmission line equations are written as [28]:

$$
-\frac{d \boldsymbol{v}(x)}{d x}=\boldsymbol{z} \boldsymbol{i}(x),-\frac{d \boldsymbol{i}(x)}{d x}=\boldsymbol{y} \boldsymbol{v}(x) \text { and } \gamma=\sqrt{\boldsymbol{z y}} .
$$

The voltage vector $\boldsymbol{v}$, current vector $\boldsymbol{i}$, impedance matrix $\boldsymbol{z}$ and admittance matrix $\boldsymbol{y}$ are defined as

$\boldsymbol{v}=\left[\begin{array}{l}v_{1} \\ v_{2}\end{array}\right], \boldsymbol{i}=\left[\begin{array}{l}i_{1} \\ i_{2}\end{array}\right], \boldsymbol{z}=\left[\begin{array}{ll}z_{11} & z_{12} \\ z_{21} & z_{22}\end{array}\right], \boldsymbol{y}=\left[\begin{array}{ll}y_{11} & y_{12} \\ y_{21} & y_{22}\end{array}\right]$

Combining the three equations (13) gives

$$
\frac{d^{2} \boldsymbol{v}(x)}{d x^{2}}=\gamma^{2} \boldsymbol{v}(x)
$$

The general solution of the second order differential equation of (15) is

$\boldsymbol{v}=\boldsymbol{C}_{\mathbf{1}} e^{\gamma x}+\boldsymbol{C}_{\mathbf{2}} e^{-\gamma x}$ and $\boldsymbol{i}=-\boldsymbol{Y}_{\boldsymbol{c}}\left(\boldsymbol{C}_{\mathbf{1}} e^{\gamma x}-\boldsymbol{C}_{\mathbf{2}} e^{-\gamma x}\right)$,

where the characteristic admittance $\boldsymbol{Y}_{c}=\boldsymbol{z}^{-1} \gamma$.

The column vectors $\boldsymbol{C}_{1}$ and $\boldsymbol{C}_{2}$ both have size $2 \times 1$. The voltages and currents at the sending and receiving ends are

$$
\boldsymbol{v}(0)=\boldsymbol{v}_{\boldsymbol{S}}, \quad \boldsymbol{i}(0)=\boldsymbol{i}_{\boldsymbol{S}}, \quad \boldsymbol{v}(\ell)=\boldsymbol{v}_{\boldsymbol{R}} \text { and } i(\ell)=\boldsymbol{i}_{\boldsymbol{R}}
$$

Inserting the boundary conditions of (17) in (16) results in

$$
\begin{aligned}
& {\left[\begin{array}{l}
\boldsymbol{v}_{S} \\
\boldsymbol{v}_{\boldsymbol{R}}
\end{array}\right]=\left[\begin{array}{cc}
\boldsymbol{I} & \boldsymbol{I} \\
e^{\gamma \ell} & e^{-\gamma \ell}
\end{array}\right]\left[\begin{array}{l}
\boldsymbol{C}_{1} \\
\boldsymbol{C}_{2}
\end{array}\right] \text { and }} \\
& {\left[\begin{array}{l}
\boldsymbol{i}_{\boldsymbol{S}} \\
\boldsymbol{i}_{\boldsymbol{R}}
\end{array}\right]=\left[\begin{array}{cc}
\boldsymbol{Y}_{\boldsymbol{c}} & \mathbf{0} \\
\mathbf{0} & \boldsymbol{Y}_{\boldsymbol{c}}
\end{array}\right]\left[\begin{array}{cc}
-\boldsymbol{I} & \boldsymbol{I} \\
-e^{\gamma \ell} & e^{-\gamma \ell}
\end{array}\right]\left[\begin{array}{l}
\boldsymbol{C}_{1} \\
\boldsymbol{C}_{\mathbf{2}}
\end{array}\right] .}
\end{aligned}
$$

The combination of (18) and (19) gives the relation between the sending an receiving voltages and currents,

$$
\left[\begin{array}{l}
\boldsymbol{i}_{\boldsymbol{S}} \\
\boldsymbol{i}_{\boldsymbol{R}}
\end{array}\right]=\left[\begin{array}{cc}
\boldsymbol{Y}_{\boldsymbol{c}} & \mathbf{0} \\
\mathbf{0} & \boldsymbol{Y}_{\boldsymbol{c}}
\end{array}\right]\left[\begin{array}{cc}
-\boldsymbol{I} & \boldsymbol{I} \\
-e^{\gamma \ell} & e^{-\boldsymbol{\gamma} \ell}
\end{array}\right]\left[\begin{array}{cc}
\boldsymbol{I} & \boldsymbol{I} \\
e^{\boldsymbol{\gamma} \ell} & e^{-\boldsymbol{\gamma} \ell}
\end{array}\right]^{-1}\left[\begin{array}{c}
\boldsymbol{v}_{\boldsymbol{S}} \\
\boldsymbol{v}_{\boldsymbol{R}}
\end{array}\right] .
$$

Inserting the following equations in (20),

$$
\begin{aligned}
& v_{S 1}=-v_{S 2}=\frac{v_{d c, S}}{2}, \quad i_{S 1}=-i_{S 2}=i_{d c, S}, \\
& v_{R 1}=-v_{R 2}=\frac{v_{d c, R}}{2}, \quad \text { and } \quad i_{R 1}=-i_{R 2}=i_{d c, R},
\end{aligned}
$$

converts the general two-phase transmission line model to the symmetrical monopole convention. For symmetric transmission lines, the resulting system simplifies to a $2 \times 2$ matrix, providing the relation between input and output currents and input and output voltages [29].

$$
\left[\begin{array}{l}
i_{d c, S} \\
i_{d c, R}
\end{array}\right]=\left[\begin{array}{ll}
Y_{11}(\omega) & Y_{12}(\omega) \\
Y_{21}(\omega) & Y_{22}(\omega)
\end{array}\right]\left[\begin{array}{l}
v_{d c, S} \\
v_{d c, R}
\end{array}\right]
$$

The frequency-dependent $(\omega)$ elements of the $2 \times 2$ matrix are functions of the impedance and admittance matrix, $\boldsymbol{z}$ and $\boldsymbol{y}$, and the transmission line length $\ell$. These impedance and admittance matrices are determined based on the dc transmission line geometry and material parameters [30].

\section{Equivalent network dc-side impedance}

Rearranging (22) gives the typical two-port representation with ABCD-parameters of a symmetrical monopole transmission line,

$$
\left[\begin{array}{l}
v_{d c, S} \\
i_{d c, S}
\end{array}\right]=\left[\begin{array}{ll}
A(\omega) & B(\omega) \\
C(\omega) & D(\omega)
\end{array}\right]\left[\begin{array}{l}
v_{d c, R} \\
i_{d c, R}
\end{array}\right] .
$$

Based on the ABDC-parameters of the different dc transmission lines and the dc inductors installed to limit the rate of rise of dc fault currents to be interrupted by adjacent dc breakers, the nodal admittance matrix $\boldsymbol{Y}_{\text {bus }}$ is obtained. The nodal admittance matrix provides the relation between the currents and voltages at each bus, $\boldsymbol{i}_{\boldsymbol{d c}}=\boldsymbol{Y}_{\boldsymbol{b u s}} \boldsymbol{v}_{\boldsymbol{d c}}$. The extended twoport representation for one branch between node $i$ and node $j$ with a dc transmission line and dc inductors with value $L_{d c}$ in each pole is

$$
\left[\begin{array}{c}
v_{d c, i} \\
i_{d c, i j}
\end{array}\right]=\left[\begin{array}{cc}
1 & 2 j \omega L_{d c} \\
0 & 1
\end{array}\right]\left[\begin{array}{cc}
A_{i j} & B_{i j} \\
C_{i j} & D_{i j}
\end{array}\right]\left[\begin{array}{cc}
1 & 2 j \omega L_{d c} \\
0 & 1
\end{array}\right]\left[\begin{array}{l}
v_{d c, j} \\
i_{d c, j i}
\end{array}\right]
$$

The multiplication of the matrices gives

$$
\left[\begin{array}{c}
v_{d c, i} \\
i_{d c, i j}
\end{array}\right]=\left[\begin{array}{c:c}
A_{i j}+C_{i j} 2 j \omega L_{d c} & B_{i j}+A_{i j} 4 j \omega L_{d c} \\
& -C_{i j} 4 \omega^{2} L_{d c}{ }^{2} \\
\hdashline C_{i j} & A_{i j}+C_{i j} 2 j \omega L_{d c}
\end{array}\right]\left[\begin{array}{c}
v_{d c, j} \\
i_{d c, j i}
\end{array}\right]
$$

The elements of the nodal admittance matrix $\boldsymbol{Y}_{\text {bus }}$ for the HVDC grid, defined as $Y_{b u s, i j}$, are now given by

$$
Y_{b u s, i j}= \begin{cases}\sum_{k} \frac{A_{i k}+C_{i k} 2 j \omega L_{d c}}{B_{i k}+A_{i k} 4 j \omega L_{d c}-C_{i k} 4 \omega^{2} L_{d c}{ }^{2}}, & \text { if } i=j, \\ -\frac{1}{B_{i j}+A_{i j} 4 j \omega L_{d c}-C_{i j} 4 \omega^{2} L_{d c}{ }^{2}}, & \text { if } i \neq j,\end{cases}
$$

where $k$ represents the adjacent nodes of node $i$.

Subsequently, the equivalent network dc-side impedance at a particular bus $Z_{b u s, i}$ can be calculated by combining 
the equations of the nodal admittance matrix and the smallsignal dc-side admittances of the MMCs which define the relation between dc voltages and currents at the remaining buses, $\Delta i_{d c}=-Y_{M M C} \Delta v_{d c}$. Doing so, the dynamics of MMCs elsewhere in the HVDC grid can be included in the equivalent network impedance. Based on the expressions of $Y_{M M C}$ and $Z_{b u s}$, the loop-gain of the MMC-based HVDC grid is obtained for analyzing the high-frequency interactions and system stability.

\section{MMC DC-SIDE ADMITTANCE ANALYSIS}

As the dc-side dynamics are largely determined by the control structure of the MMC, this section analyzes in detail the effect of different types of the outer control on the MMC dc-side admittance $Y_{M M C}(s)$. Furthermore, the accuracy of the MMC dc-side admittance model is validated to assess its applicability for the stability analysis of dc-side highfrequency interactions in MMC-based HVDC grids.

\section{A. Impact of outer control on dc-side admittance}

The dependency of the MMC dc-side admittance on the outer control is represented by the transfer function $M(s)$ in (8) which gives the relation between the linearized d-axis output current reference and dc voltage,

$$
\Delta i_{s d}^{*}(s)=M(s) \Delta v_{d c}
$$

To understand its impact on $Y_{M M C}(s), M(s)$ is studied for the three types of outer controls depicted in Fig. 4. For a dc voltage and active power controlling MMC, $M(s)$ is shown to be

$$
M_{d v c}(s)=\frac{-2 v_{d c, 0} C_{d v c}(s) F(s)^{2}}{v_{g}^{d}} \quad \text { and } \quad M_{p}(s)=0,
$$

according to [26] and [31] respectively. The expression of $M(s)$ for a droop-controlled MMC can be derived based on the droop control depicted in Fig. 4. The d-axis current reference for a droop-controlled MMC is determined by

$$
i_{s d}^{*}(s)=\frac{C_{p}(s)}{v_{d g}}\left(P_{g}^{*}+g_{d c}\left(v_{d c}^{*}-F(s) v_{d c}\right)-F(s) P_{g}\right) \text {. }
$$

The active power at the PCC for a power-invariant dq-frame with d-axis perfectly aligned to $v_{g}$ is

$$
P_{g}=v_{g d} i_{s d}+v_{g q} i_{s q}=v_{g d} i_{s d} .
$$

Combining (29) and (30) and linearizing, yields

$$
\Delta i_{s d}^{d *}(s)=\frac{C_{p}(s)}{v_{g d}}\left(-g_{d c} F(s) \Delta v_{d c}-F(s) v_{g d} \Delta i_{s d}\right) .
$$

By making use of the relation between the ac currents and ac current references in (10), $\Delta i_{s d}(s)=G_{c c 11}(s) \Delta i_{s d}^{*}(s)$ for $\Delta i_{s q}^{*}(s)=0$. The transfer function $M_{d r p}(s)$ is then equal to

$$
M_{d r p}(s)=\frac{\Delta i_{s d}^{*}}{\Delta v_{d c}}=\frac{-C_{p}(s) g_{d c} F(s)}{v_{g d}\left(1+C_{p}(s) F(s) G_{c c 11}(s)\right)} .
$$

The transfer function $G_{c c 11}(s)$ represents the closed-loop system of the d-axis output current control loop as shown in (10). In this paper, the output current control is tuned to

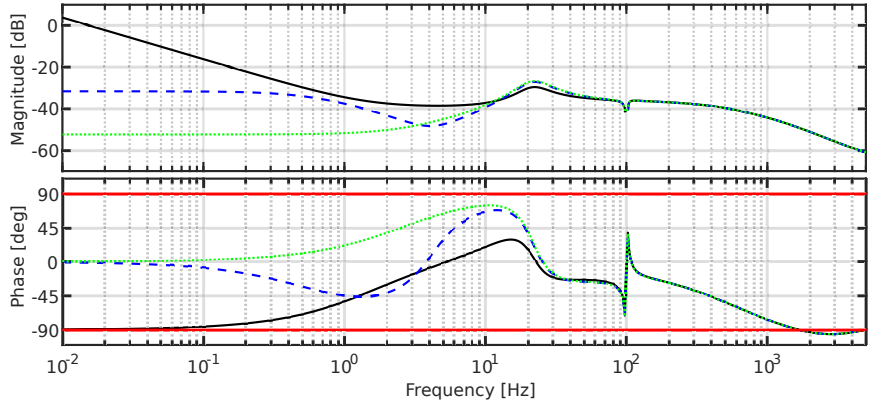

Fig. 6. Comparison of MMC analytical dc-side admittance $Y_{M M C}$ with $P_{g}$ $=1000 \mathrm{MW}$ for different outer control loops: DVC (solid black line), droop (dashed blue line) and $\mathrm{P}$ (dotted green line).

obtain a bandwidth $\alpha_{o c c}$ of $500 \mathrm{~Hz}$. Consequently, $G_{c c 11}(s)$ can assumed to be equal to 1 below $100 \mathrm{~Hz}$. The transfer functions $M_{d v c}(s)$ and $M_{d r p}(s)$ are then rewritten as

$$
\begin{aligned}
& M_{d v c}(s)=\left(\frac{-2 v_{d c, 0} K_{i, d v c}}{v_{g d}}\right) \frac{\left(\frac{K_{p, d v c}}{K_{i, d v c}}+1\right)}{s\left(\frac{s}{\alpha_{f}}+1\right)^{2}} \text { and } \\
& M_{d r p}(s)=\left(\frac{-\alpha_{f} K_{i, p}}{v_{g d}}\right) \frac{g_{d c}\left(\frac{K_{p, p}}{K_{i, p}} s+1\right)}{s^{2}+\alpha_{f}\left(1+K_{p, p}\right) s+K_{i, p} \alpha_{f}},
\end{aligned}
$$

where $\alpha_{f}$ is the bandwidth of the first-order filter $F(s)$.

As an example, the Bode plot of the dc-side admittance $Y_{M M C}(s)$ is shown in Fig. 6 for the three outer control loops where the circuit and control parameters of the MMC are according to Table III in the Appendix. The circuit parameters are based on a 401-level MMC [32] and the control parameters are calculated according to [26], [33]. The duration of the time delay $T_{d}$ is $150 \mu \mathrm{s}$ [34]. Inserting these parameters in (33) and (34) results in a transfer function $M_{d v c}(s)$ with a zero at $10 \mathrm{rad} / \mathrm{s}$ and a pole at the origin. In addition, a double pole is located at $314 \mathrm{rad} / \mathrm{s}$, resulting in an amplitude decay of $-40 \mathrm{~dB} / \mathrm{dec}$ above this frequency. For the droop-controlled MMC, $M_{d r p}(s)$ has a zero at $78.6 \mathrm{rad} / \mathrm{s}$ and poles at 3.79 and $326 \mathrm{rad} / \mathrm{s}$, causing a decay of $-20 \mathrm{~dB} / \mathrm{dec}$ from $326 \mathrm{rad} / \mathrm{s}$ onwards. Consequently, the amplitude of both transfer functions approaches zero in the higher frequency range, coinciding with $M_{p}(s)$. This is confirmed by Fig. 6 which indicates that the three Bode plots practically coincide for the frequency range above $50 \mathrm{~Hz}$. At $100 \mathrm{~Hz}$, the resonant effect of the circulating current control PR-controller from (4) is visible.

Important to notice in Fig. 6 is the area of non-passivity of the MMC dc-side admittance in the range between 1 and $5 \mathrm{kHz}$. A transfer function is considered to be non-passive if its phase angle exceeds the area between $-90^{\circ}$ and $90^{\circ}$, indicated by the red lines. The non-passivity of the MMC can be detrimental for the system stability as this causes a positive feed-back behavior in the closed-loop system representation.

\section{B. Validation of dc-side admittance model}

The non-passivity of the MMC dc-side admittance is more clearly observed in Fig. 7, which depicts a zoom-in of the Bode plot of $Y_{M M C}$ from 1 to $5 \mathrm{kHz}$. The accuracy of the MMC analytical dc-side admittance model in this frequency 


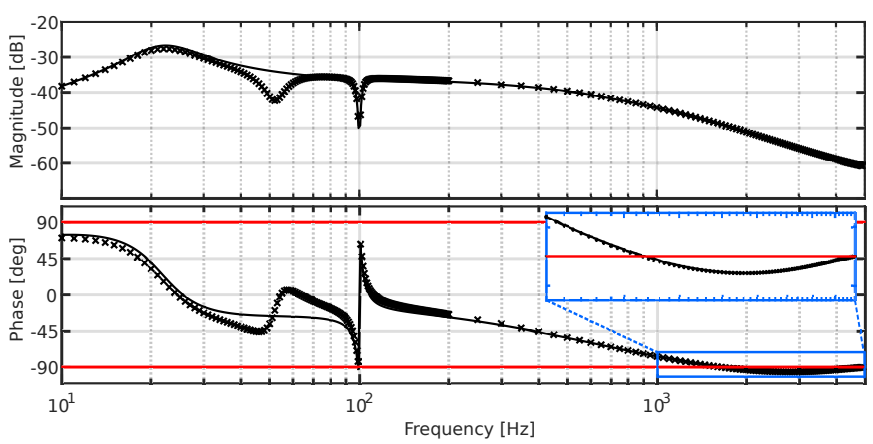

Fig. 7. Bode plot of MMC dc-side admittance $Y_{M M C}$ with active power control and $P_{g}=1000 \mathrm{MW}$ : Analytical model (solid black line) and frequency sweep (black crosses).

range is validated by performing a frequency sweep on the nonlinear MMC model implemented in the EMT-software PSCAD. This frequency sweep involves the superposition of a voltage perturbation with varying frequency on the dc voltage at the terminals of the MMC. By performing a Fast Fourier Transform on the time-domain data of the resulting $v_{d c}$ and $i_{d c}$, the MMC dc-side admittance is obtained as indicated by the black crosses in Fig. 7. According to Fig. 7, there is a deviation of the frequency sweep compared to the analytical model in the lower frequency range, mainly around $50 \mathrm{~Hz}$. This deviation is caused by the multi-harmonic response of the MMC, which is taken into account in the frequency sweep, while this is not the case for $Y_{M M C}$ [26]. However, it is clear from Fig. Fig. 7 that the multi-harmonic response of the MMC has limited to no effect on the MMC high-frequency dynamics as the analytical model and frequency sweep closely coincide. Hence, it can be concluded that the analytically derived $Y_{M M C}$ is capable of representing the MMC dynamics with high accuracy in the area of non-passivity. The impact of this non-passivity on the harmonic stability of the MMC-based HVDC grid is further analyzed in Section IV.

\section{RESULTS AND DISCUSSION}

In this section, the high-frequency interactions between an individual MMC and HVDC grid resonances are analyzed by studying their combined effect on the system stability. The impact of the MMC dynamics and dc system resonances on the stability is assessed using the analytical impedance-based method discussed in Section II. The focus of the analysis is on interactions in the frequency range of the MMC non-passivity, that is, from 1 to $5 \mathrm{kHz}$.

\section{A. Four-terminal test system}

The impedance-based stability analysis is applied to the four-terminal HVDC system depicted in Fig. 8. This HVDC grid configuration is based on the four-terminal Zhangbei HVDC system [35], although a symmetrical monopolar topology has been assumed instead of a bipolar one. The four halfbridge MMCs, with parameters according to Table III in the Appendix, are interconnected via dc overhead lines and dc inductors are installed at every pole to limit the rate of rise of fault current in adjacent dc breakers. The length of the overhead lines $\ell$ and dc inductance value $L_{d c}$ are summarized

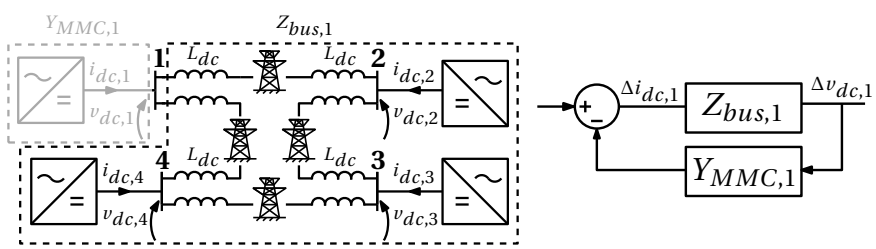

Fig. 8. Closed-loop representation of four-terminal MMC-based HVDC grid test system with overhead lines and fault-current limiting inductors

TABLE I

HVDC GRID TEST SYSTEM OHL LENGTHS AND DC INDUCTANCE VALUE

\begin{tabular}{lllll}
\hline & Line 12 & Line 23 & Line 34 & Line 41 \\
\hline$\ell$ & $227 \mathrm{~km}$ & $126 \mathrm{~km}$ & $219 \mathrm{~km}$ & $66 \mathrm{~km}$ \\
$L_{d c}$ & $200 \mathrm{mH}$ & $200 \mathrm{mH}$ & $200 \mathrm{mH}$ & $200 \mathrm{mH}$ \\
\hline
\end{tabular}

in Table I [35]. The overhead line geometry is based on the HVDC tower structure described in [36].

The MMC dc-side admittance and the equivalent network dc-side impedance at bus 1 are obtained as described in Section II. While performing the analysis, the MMC at bus 1 is set to dc voltage control whereas the other MMCs are controlling their active power to a constant value. Subsequently, the stability of the resulting four-terminal system is assessed based on the Nyquist plot of the loop-gain $Y_{M M C, 1} Z_{b u s, 1}$, in which the equivalent bus impedance $Z_{b u s, 1}$ accounts for the presence of the three power-controlling MMCs. The subsystems $Y_{M M C, 1}$ and $Z_{b u s, 1}$ are checked to be stable upfront by connecting them to an ideal load and source respectively. This assures that there are no open-loop poles in the right half plane and instability only occurs when the two subsystems are interconnected [24]. Hence, the system stability can be determined by the encirclements of the Nyquist plot's encirclements of the $(-1,0)$ point in the complex plane. The analytical transfer functions are implemented in MATLAB to obtain the Nyquist curves. As a benchmark, the four-terminal MMC-based HVDC grid is in addition modeled in the EMT-software PSCAD. The frequency-dependent phase model and averaged model are used to represent the overhead lines and MMCs respectively.

\section{B. Impact of dc resonances on system stability}

To illustrate the impact of dc resonances present in the equivalent network impedance $Z_{b u s}$ on the system stability, the impedance-based analysis of the four-terminal system is performed for variations in 1) the fault current-limiting inductors, 2) the grid topology and 3) the transmission line length.

1) DC inductor variations: The Nyquist plot of $Y_{M M C, 1} Z_{b u s, 1}$ is shown in Fig. 9a for the ring topology of the HVDC grid with de inductors of $200 \mathrm{mH}$. For all Nyquist plots in this paper, the point $(-1,0)$ is indicated with a red cross and the unity circle with a dashed red line. According to the plot, the -1 point on the real axis is not encircled which means that the system is stable for this configuration. This demonstrates that although the MMC behaves non-passive, this does not necessarily lead to instability of the system. However, the dc inductance value is dependent on the 


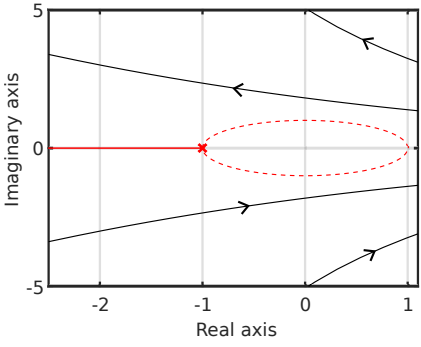

(a)

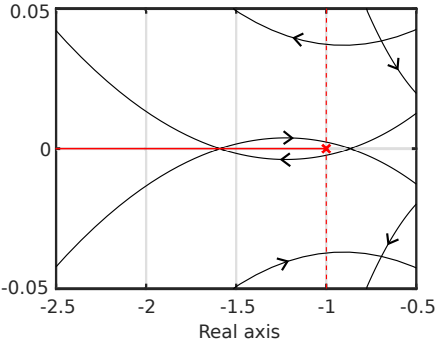

(b)
Fig. 9. Nyquist plot of $Y_{M M C, 1} Z_{b u s, 1}$ for ring topology (a) with $L_{d c}=$ $200 \mathrm{mH}$; (b) with $L_{d c}=15 \mathrm{mH}$.

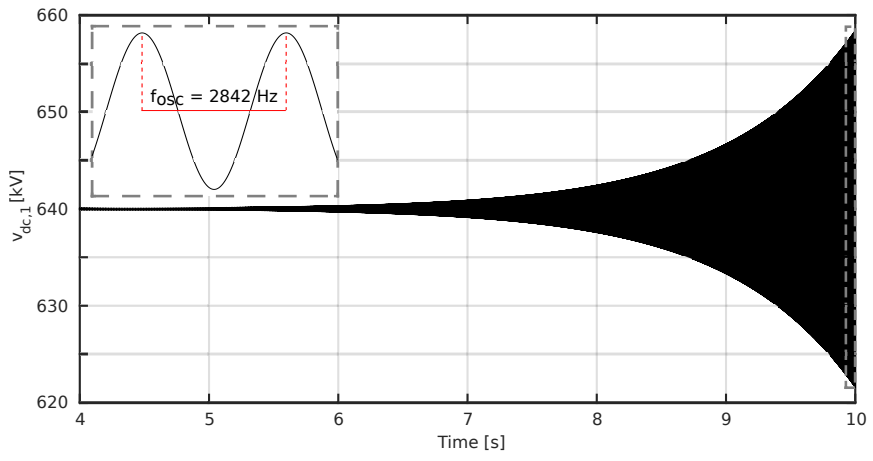

Fig. 10. Time-domain verification - DC voltage $v_{d c, 1}$ for ring topology with $L_{d c}=15 \mathrm{mH}$

accepted converter operational requirements and protection strategy, and can vary over a wide range from approximately $10 \mathrm{mH}$ to $300 \mathrm{mH}$ [37], [38]. If the fault current-limiting inductors are reduced to a value of $15 \mathrm{mH}$, a clockwise encirclement around -1 appears at Fig. 9b. The HVDC grid is unstable in this condition as confirmed by the time-domain simulation in PSCAD depicted in Fig. 10. The figure shows how the voltage at bus 1 increases in an unstable way with an oscillation frequency $f_{\text {osc }}$ of $2842 \mathrm{~Hz}$, eventually reaching an unacceptable voltage level. This demonstrates the risk of harmonic instability due to interaction between the MMC non-passivity and high-frequency dc resonances.

Fig. 11 shows the Bode plot of $Z_{b u s, 1}$ in the frequency range of the MMC non-passivity for values of $L_{d c}$ varying from $200 \mathrm{mH}$ to $15 \mathrm{mH}$ in steps of $25 \mathrm{mH}$. As it is clear from the Bode plot, the increase in dc inductance value lowers the resonance frequencies and generally causes a more inductive behaviour of $Z_{b u s}$ as the phase angle remains closer to $90^{\circ}$. It should be noted that $Z_{b u s}$ is passive for all dc inductance values, which is a sufficient condition for stability of the subsystem [39]. However, from the Bode plot of $Z_{b u s, 1}$ alone it is not possible to clearly determine how the dc inductance value affects the stability of the entire system.

To do so, the phase margin $(P M)$ and corresponding gain cross-over frequency $f_{G C}$ of the loop-gain $Y_{M M C, 1} Z_{b u s, 1}$ are calculated based on the Nyquist plot for different values of $L_{d c}$ in Table II. For some values of $L_{d c}$ there are multiple $0 \mathrm{~dB}$-crossings as a consequence of the dc resonances. Hence, only the minimum phase margin is given as this indicates the stability limit. It should be noted that the system becomes unstable if the phase margin is negative. Confirmed by the time-domain verification in Fig. 10, the frequency of the

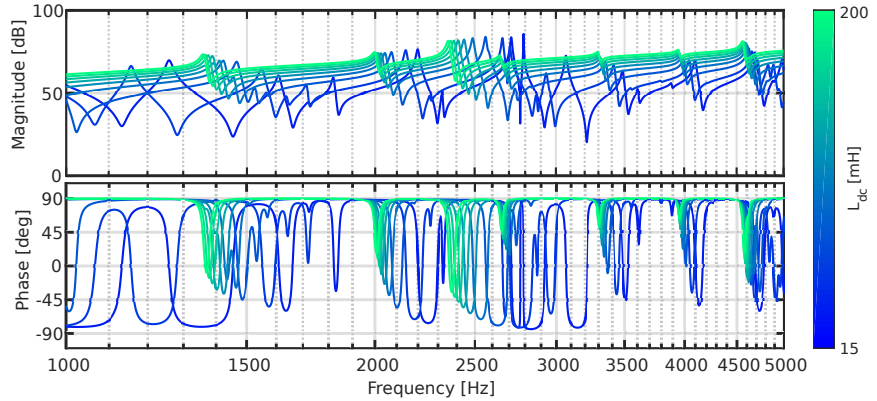

Fig. 11. Bode plot of $Z_{b u s, 1}$ for ring topology with $L_{d c}$ varying from $200 \mathrm{mH}$ to $15 \mathrm{mH}$ in steps of $25 \mathrm{mH}$

TABLE II

$P M$ AND $f_{G C}$ FOR VARYING VALUES OF $L_{d c}$

\begin{tabular}{cccccc}
\hline$L_{d c}[\mathrm{mH}]$ & $P M\left[^{\circ}\right]$ & $f_{G C}[\mathrm{~Hz}]$ & $L_{d c}[\mathrm{mH}]$ & $P M\left[^{\circ}\right]$ & $f_{G C}[\mathrm{~Hz}]$ \\
\hline 15 & -0.14 & 2842 & 125 & 53.47 & 2456 \\
25 & 2.22 & 2779 & 150 & 88.48 & 2431 \\
50 & 5.63 & 2649 & 175 & $\infty$ & $/$ \\
75 & 18.09 & 2553 & 200 & $\infty$ & $/$ \\
100 & 33.36 & 2494 & & & \\
\hline
\end{tabular}

unstable oscillation depicted is equal to the corresponding gain cross-over frequency of the negative phase margin. As the phase margins increases when $L_{d c}$ increases, it can indeed be concluded that a larger dc inductor, which have in the past been identified as potential sources of problems in a lower frequency range [40], [41], on the contrary has a stabilizing effect on oscillations in the higher frequency range.

2) HVDC grid topological changes: The four-terminal HVDC grid is potentially operated as a radial topology due to e.g. an overhead line outage. The change from a ring to a radial topology impacts the electromagnetic characteristics of the grid. The dc resonances are shifted, which can lead to negative interactions with the converter's non-passivity region. The case in which the overhead line between bus 3 and 4 is disconnected is analyzed in Fig. 12. Fig. 12a shows that the four-terminal system with $L_{d c}$ equal to $200 \mathrm{mH}$ is again stable. In contrast to the ring topology, the HVDC grid now becomes unstable with fault current-limiting inductors of $21 \mathrm{mH}$ or lower as depicted in Fig. 12b. The dc voltage at bus 1 starts to oscillate with a frequency of $2700 \mathrm{~Hz}$ as depicted by the PSCAD time-domain simulation in Fig. 13, increasing the voltage to $740 \mathrm{kV}$ after approximately $3.5 \mathrm{~s}$. As a change in operating mode of the HVDC grid shifts the dc resonances, it is vital to analyze the stability for every possible operating topology of the grid.

3) Overhead line length variations: To assess the influence of the overhead line length on the system stability, a four-terminal MMC-based HVDC system without fault current-limiting inductors is analyzed. The Nyquist plot of $Y_{M M C, 1} Z_{b u s, 1}$ for the ring topology of the HVDC grid with $L_{d c}$ equal to zero and with the length of the overhead lines according to Table $\mathrm{I}$ is shown in Fig. 14a. One clockwise encirclement around the -1 point is observed, indicating that the closed-loop system is unstable. To determine the impact of the overhead line length on the system stability, the length of the four overhead lines are gradually increased until the HVDC grid is found to be stable according to the Nyquist 


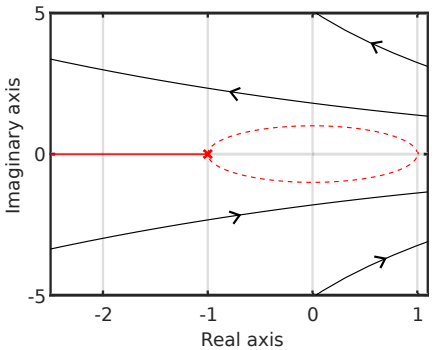

(a)

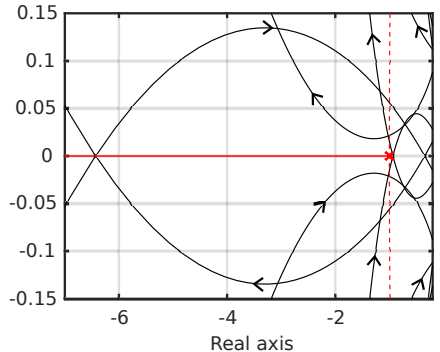

(b)
Fig. 12. Nyquist plot of $Y_{M M C, 1} Z_{b u s, 1}$ for a radial topology (line 34 disconnected) with (a) $L_{d c}=200 \mathrm{mH}$; (b) $L_{d c}=21 \mathrm{mH}$.

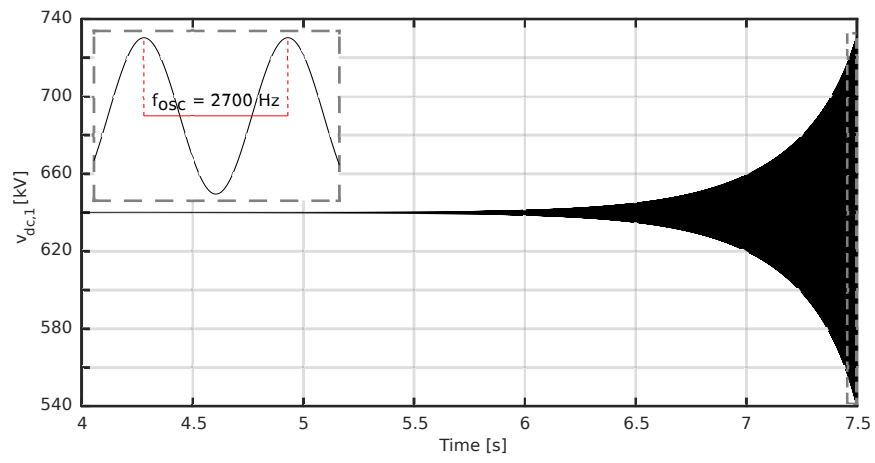

Fig. 13. Time-domain verification $-\mathrm{DC}$ voltage $v_{d c, 1}$ for a radial topology (line 34 disconnected) and $L_{d c}=21 \mathrm{mH}$.

stability criterion. If the lengths of the four overhead lines are increased to 2.2 times their original length, the -1 encirclement disappears as shown in Fig. 14b. As the overhead line resonances shift to the lower frequency range when the length is increased, longer OHLs seem to be beneficial to avoid negative interactions with the MMC's range of non-passivity.

\section{Impact of MMC dynamics on system stability}

The previous section discussed how passive grid components, e.g. dc inductors and transmission lines, impact the dc resonances appearing in $Z_{b u s}$ and consequently the harmonic stability. The root cause of the instability is however the non-passive behavior of the MMC as this leads a positive feedback effect with amplification of the resonances present in the HVDC grid. The MMC dc-side admittance $Y_{M M C}$ can be reshaped by adapting the control parameters. In Section III, it was demonstrated that the outer control has no effect on the

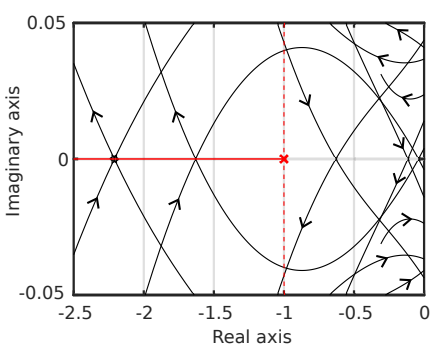

(a)

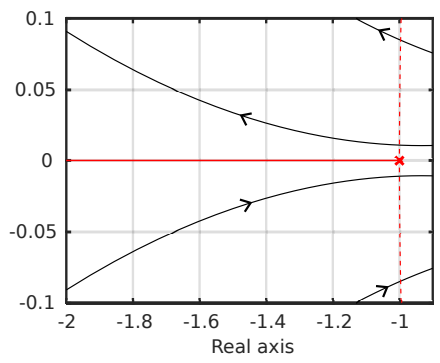

(b)
Fig. 14. Nyquist plot of $Y_{M M C, 1} Z_{b u s, 1}$ for ring topology without dc inductors and (a) the original overhead line lengths; (b) 2.2 times the overhead line lengths.

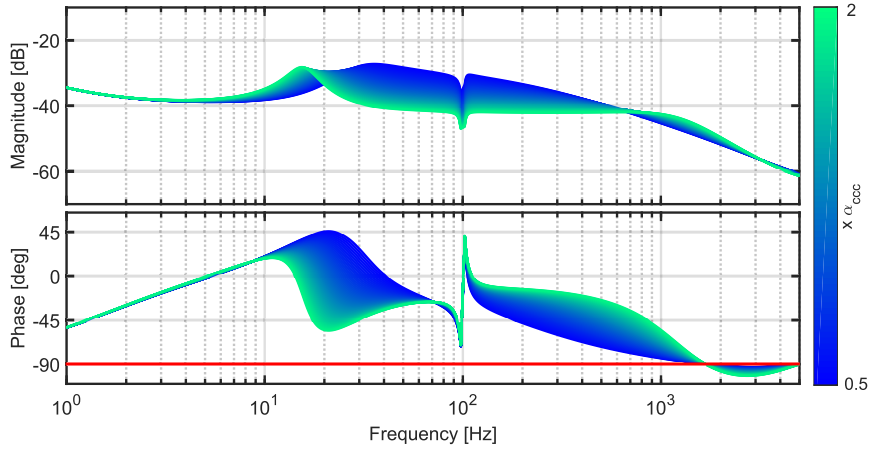

Fig. 15. Bode plot of MMC dc-side admittance $Y_{M M C}$ with de voltage control and $P_{g}=1000 \mathrm{MW}$ for varying values of the circulating current control bandwidth $\alpha_{c c c}$.

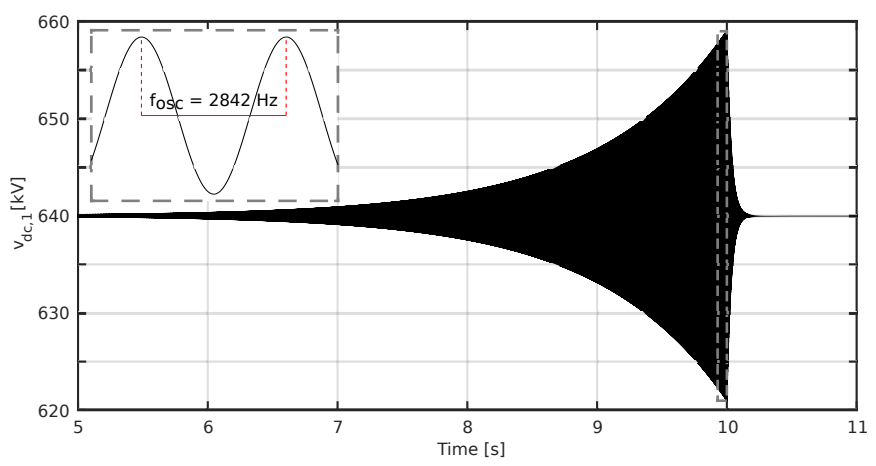

Fig. 16. Time-domain verification - DC voltage $v_{d c, 1}$ for a ring topology with $L_{d c}=15 \mathrm{mH}$. At $t=10 \mathrm{~s}, \alpha_{c c c}$ is reduced to half of its original value.

non-passivity in the kHz-range but it does influence the system interactions in the lower frequency [16], [18], [19]. However, the non-passivity in the kHz-range can still be affected by the inner control loops and time delay.

1) Circulating current controller variations: In Fig. 15, the Bode plot of the dc-side admittance for a dc voltage controlling MMC with varying values of the circulating current control bandwidth, $\alpha_{c c c}$, is given. The bandwidth is increased from $150 \mathrm{~Hz}$ to $600 \mathrm{~Hz}$. Fig. 15 shows that the non-passivity in the range of 1 to $5 \mathrm{kHz}$ decreases when $\alpha_{c c c}$ has a lower value. This is confirmed by Fig. 16, which gives the time-domain signal of $v_{d c, 1}$ from PSCAD for the unstable case of a ring topology with $L_{d c}$ equal to $15 \mathrm{mH}$. At time equals $10 \mathrm{~s}, \alpha_{c c c}$ is reduced to half of its original value which stabilizes the system. It is important to notice that, although lowering $\alpha_{c c c}$ has a positive effect on the system stability by reducing the nonpassivity, the phase angle of $\alpha_{c c c}$ is changed in other frequency regions which results in a decreased dynamic performance of the MMC. This substantial impact of the circulating current controller differs significantly from observations at the ac side, where this control loop has been shown to have little effect on high-frequency interactions with grid resonances [12].

2) Output current controller variations: The Bode plot of Fig. 17 shows that varying the bandwidth of the output current controller bandwidth $\alpha_{c c c}$ has limited effect on the non-passivity of the dc-side impedance, for a variation from $250 \mathrm{~Hz}$ until $1000 \mathrm{~Hz}$. This can be explained by the analytical expression of the dc-side MMC admittance where the dynamics of the output current controller $C_{o c c}(s)$ are included in the 


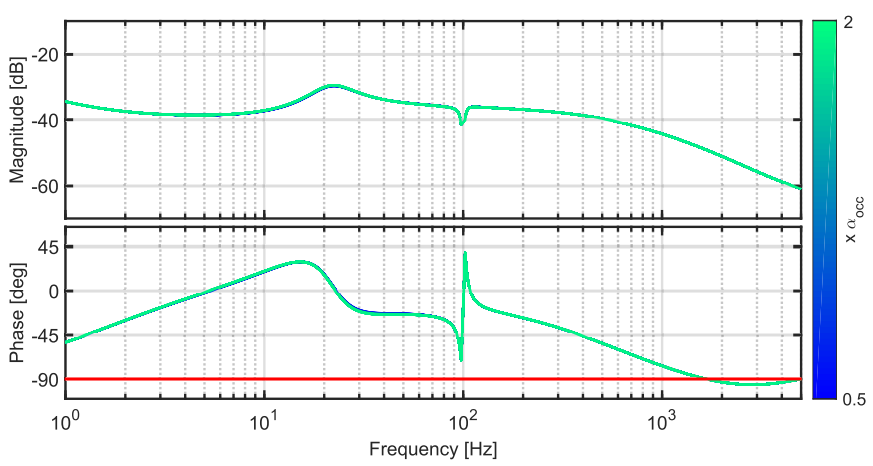

Fig. 17. Bode plot of MMC dc-side admittance $Y_{M M C}$ with dc voltage control and $P_{g}=1000 \mathrm{MW}$ for varying values of the output current control bandwidth $\alpha_{o c c}$.

matrices $\boldsymbol{K}_{s}$ and $\boldsymbol{G}_{\boldsymbol{c c}}$ of (11). According to (8) and (9), the elements of $\boldsymbol{K}_{s}$ and $\boldsymbol{G}_{\boldsymbol{c c}}$ only appear in combination with the transfer function $M(s)$ which represents the influence of the outer control. As discussed in Section III, $M(s)$ is dominated by its slower poles, causing the transfer function to approach zero in the higher frequency range. This cuts off the dynamics of the output current controller, making the effect on the MMC dc-side impedance negligible. It is important to point out that this observation differs when compared to the MMC ac-side admittance, which is largely depending on the output current control in the higher frequency range [42].

3) Time delay duration variations: In Fig. 18, the Bode plot of the dc-side admittance for a dc voltage controlling MMC with varying values of the converter time delay duration, $T_{d}$, is given. The time delay duration is increased from $75 \mu \mathrm{s}$ until $300 \mu$ s. Larger values for the time delay duration enlarge the area of non-passivity and shift it to lower frequencies, indicating that the MMC could even start to negatively interact with lower frequency dc resonances in this case. When the overall time delay is lowered, for example by reducing the required time for the calculation of voltage references, modulation and submodule balancing, the region of non-passivity becomes smaller, which improves the system stability. Moreover, changing the value of the time delay duration mainly has an effect on the higher frequency dynamics in contrast to the variation of $\alpha_{c c c}$, which was noticeable over a much broader frequency range. The observations are in line with those made for ac-side harmonic stability of VSC-HVDC systems, namely that the converter ac-side admittance can exhibit non-passivity due to the equivalent time delay, which is detrimental for the system stability [12].

The effect of the time delay on the stability is further verified by the analysis of two cases. In the first case, the time delay of $Y_{M M C}$ is increased from 150 to $300 \mu$ and the stability is assessed for an HVDC grid with ring topology and $\mathrm{dc}$ inductors of $15 \mathrm{mH}$. The time-domain simulation of Fig. 19a shows that there is an unstable oscillation of $1349 \mathrm{~Hz}$ in the system. This frequency is almost half of the oscillation frequency when the time delay is $150 \mu$ s. The lower oscillation frequency can be explained by the shift of the area of non-passivity to the lower frequencies when the time delay increases as indicated in Fig. 18. In the second case, the time delay is reduced to $75 \mu$ s. According to Fig. 19b, the system is

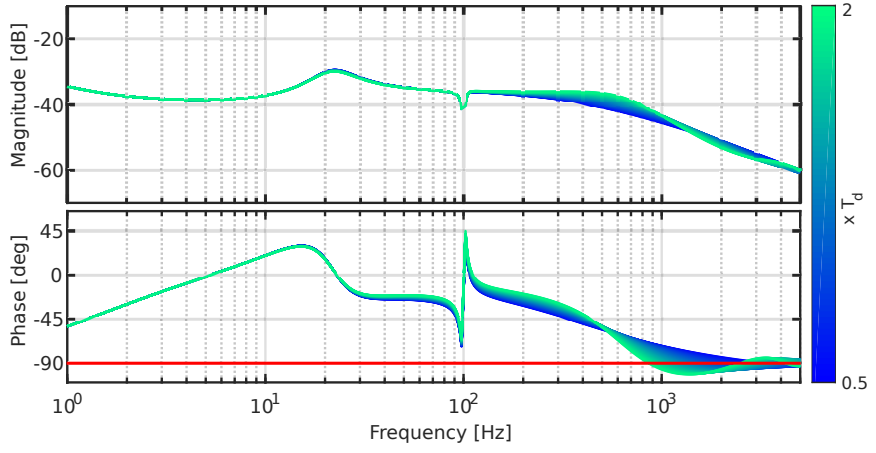

Fig. 18. Bode plot of MMC dc-side admittance $Y_{M M C}$ with dc voltage control and $P_{g}=1000 \mathrm{MW}$ for varying values of the time delay duration $T_{d}$.

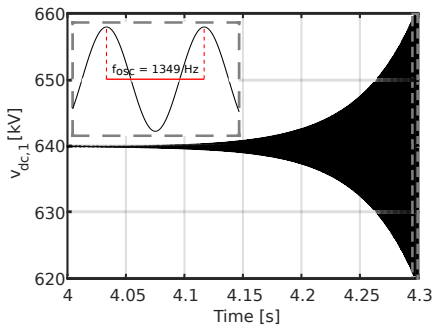

(a)

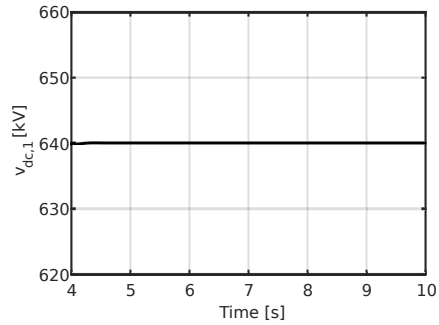

(b)
Fig. 19. Time-domain verification - DC voltage $v_{d c, 1}$ for a ring topology with $L_{d c}=15 \mathrm{mH}$ and for $Y_{M M C, 1}$ with (a) a time delay of $300 \mu \mathrm{s}$; (b) a time delay of $75 \mu \mathrm{s}$.

now stable as the dc voltage now remains at its reference. This is again in line with the results from Fig. 18, since lowering the overall time delay reduces the region of non-passivity, which in turn tends to improve the system stability.

\section{CONClusion}

The analysis of the dc-side harmonic stability of an MMCbased HVDC grid by an impedance-based approach in this paper demonstrates that unstable high-frequency dc-side interactions can take place in an MMC-based HVDC grid with overhead lines. The interactions bear some similarities to recently reported high-frequency ac-side interactions of reallife VSC-HVDC systems. The paper shows that the MMC dc-side admittance has an area of non-passivity in the highfrequency range which can negatively interact with dc system resonances, potentially giving rise to instability of the entire HVDC grid.

A detailed assessment of the impact of the HVDC grid resonances leads to the conclusion that dc systems with longer overhead lines tend to be less prone to high-frequency stability problems due to lower system resonance frequencies. Similarly, larger fault current-limiting inductors have a stabilizing effect in the area of the MMC non-passivity as they shift the frequency range of the dc resonances and increase the stability margin. Moreover, a stability analysis for every possible operational topology of the HVDC grid is vital as also topological changes affect the dc resonances.

Concerning the MMC internal dynamics, measures taken to lower the converter equivalent time delay reduce the nonpassivity of the MMC dc-side admittance and the risk towards high-frequency interactions, which is in line with earlier 
observations regarding the MMC ac-side admittance. Outer control loops, i.e dc voltage control, active power control and droop control, prevailing the converter's dc-side response at lower frequencies and thus reported as having a significant influence on low-frequency system interactions, are shown to have a negligible effect on the MMC's area of non-passivity and thus on the high-frequency system interactions. Different compared to the MMC's ac-side, the MMC dc-side admittance is largely independent on the output current control dynamics in the higher frequency range. Equally different from the MMC's ac-side, the circulating current control is shown to have a significant impact. Lowering its bandwidth reduces the converter's non-passivity and thus potentially mitigating the problem, at the cost of decreasing its dynamic performance.

\section{APPENDIX}

TABLE III

CIRCUIT AND CONTROL PARAMETERS OF MMC

\begin{tabular}{lll}
\hline Par. & Description & Value \\
\hline$S_{n}$ & Nominal power & $1000 \mathrm{MVA}$ \\
$v_{g}$ & Rated line-to-line PCC voltage & $320 \mathrm{kV}$ \\
$v_{d c}$ & Rated pole-to-pole dc voltage & $640 \mathrm{kV}$ \\
$\omega_{1}$ & Fundamental angular frequency & $100 \pi \mathrm{rad} / \mathrm{s}$ \\
$N$ & Number of submodules per arm & 400 \\
$C$ & Capacitance per submodule & $10 \mathrm{mF}$ \\
$L_{c}$ & Arm inductance & $50 \mathrm{mH}$ \\
$L_{f}$ & Equivalent transformer inductance & $60 \mathrm{mH}$ \\
$L_{t}$ & Total equivalent inductance & $85 \mathrm{mH}$ \\
$R_{c}$ & Arm resistance & $1.07 \Omega$ \\
$R_{f}$ & Equivalent transformer resistance & $0.535 \Omega$ \\
$R_{t}$ & Total equivalent resistance & $1.07 \Omega$ \\
$\alpha_{o c c}$ & Bandwidth of OCC & $1000 \pi \mathrm{rad} / \mathrm{s}$ \\
$K_{p, o c c}$ & Proportional gain of OCC & 267 \\
$K_{i, o c c}$ & Integral gain of OCC & 3362 \\
$\alpha_{c c c}$ & Bandwidth of CCC & $600 \pi \mathrm{rad} / \mathrm{s}$ \\
$R_{a}$ & Proportional gain of CCC & 94.25 \\
$K_{r, c c c}$ & Resonant gain of CCC & 42.8 \\
$\alpha_{d v c}$ & Bandwidth of DVC & $25 \pi \mathrm{rad} / \mathrm{s}$ \\
$K_{p, d v c}$ & Proportional gain of DVC & 0.005 \\
$K_{i, d v c}$ & Integral gain of DVC & 0.05 \\
$\alpha_{p}$ & Bandwidth of P & $25 \pi \mathrm{rad} / \mathrm{s}$ \\
$K_{p, p}$ & Proportional gain of P & 0.05 \\
$K_{i, p}$ & Integral gain of P & 3.93 \\
$g_{d c}$ & Droop constant & $10 \mathrm{pu}$ \\
$T_{d}$ & Time delay & $150 \mu \mathrm{s}$ \\
$\alpha_{f}$ & Bandwidth of outer control filter & $100 \pi \mathrm{rad} / \mathrm{s}$ \\
$\alpha_{f o c c}$ & Bandwidth of OCC filter & $100 \pi \mathrm{rad} / \mathrm{s}$ \\
$\alpha_{f c c c}$ & Bandwidth of CCC filter & $60 \pi \mathrm{rad} / \mathrm{s}$ \\
\hline & &
\end{tabular}

\section{REFERENCES}

[1] N. Ahmed, S. Norrga, H.-P. Nee, A. Haider, D. Van Hertem, L. Zhang, and L. Harnefors, "HVDC supergrids with modular multilevel converters - The power transmission backbone of the future," in Proc. IEEE SSD, Chemnitz, Germany, Mar. 2012, 7 pages.

[2] N. Ahmed, L. Ängquist, S. Norrga, A. Antonopoulos, L. Harnefors, and H.-P. Nee, "A computationally efficient continuous model for the modular multilevel converter," IEEE Trans. Emerg. Sel. Top. Power Electron., vol. 2, no. 4, pp. 1139-1148, Dec. 2014.

[3] E. Möllerstedt and B. Bernhardsson, "Out of control because of harmonics - An analysis of the harmonic response of an inverter locomotive," IEEE Control Syst. Mag., pp. 70-81, Aug. 2000.
[4] C. Buchhagen, C. Rauscher, A. Menze, and J. Jung, "BorWin1 - First experiences with harmonic interactions in converter dominated grids," in Proc. Int. ETG Congr., Bonn, Germany, Nov. 2015, pp. 27-33.

[5] M. Koochack Zadeh, T. Rendell, C. Rathke, and A. Menze, "Operating experiences of HVDC links - Behaviour during faults and switching events in the onshore grid," in Proc. CIGRE B4 Colloq., Winnipeg, Canada, Oct. 2017, 8 pages.

[6] H. Saad, Y. Vernay, S. Dennetiere, P. Rault, and B. Clerc, "System dynamic studies of power electronics devices with real-time simulation - A TSO operational experience," in Proc. CIGRE Conf., Paris, France, Aug. 2018.

[7] I. Erlich, B. Paz, M. K. Zadeh, S. Vogt, C. Buchhagen, C. Rauscher, A. Menze, and J. Jung, "Overvoltage phenomena in offshore wind farms following blocking of the HVDC converter," in Proc. IEEE PES Gen. Meet., Boston, US, Jul. 2016, 5 pages.

[8] C. Zou, H. Rao, S. Xu, Y. Li, W. Li, J. Chen, X. Zhao, Y. Yang, and B. Lei, "Analysis of resonance between a VSC-HVDC converter and the AC grid," IEEE Trans. Power Electron., vol. 33, no. 12, pp. $10157-$ 10168 , Dec. 2018.

[9] L. Harnefors, X. Wang, A. G. Yepes, and F. Blaabjerg, "Passivity-based stability assessment of grid-connected VSCs - An overview," IEEE J. Emerg. Sel. Top. Power Electron., vol. 4, no. 1, pp. 116-125, Mar. 2016.

[10] X. Wang and F. Blaabjerg, "Harmonic stability in power electronicbased power systems: concept, modeling, and analysis," IEEE Trans. Smart Grid, vol. 10, no. 3, pp. 2858-2870, May 2019.

[11] R. Shah, J. C. Sánchez, R. Preece, and M. Barnes, "Stability and control of mixed AC-DC systems with VSC-HVDC: a review," IET Gener. Transm. Distrib., vol. 12, no. 10, pp. 2207-2219, Apr. 2018.

[12] A. Bayo-Salas, "Control interactions in power systems with multiple VSC HVDC converters," Ph.D. dissertation, KU Leuven, Aug. 2018.

[13] H. Zhang, L. Harnefors, X. Wang, H. Gong, and J. P. Hasler, "Stability analysis of grid-connected voltage-source converters using SISO modeling," IEEE Trans. Power Electron., vol. 34, no. 8, pp. 8104-8117, Aug. 2019.

[14] A. Bayo-Salas, J. Beerten, and D. Van Hertem, "Analytical methodology to develop frequency-dependent equivalents in networks with multiple converters," in Proc. IEEE PowerTech, Manchester, UK, Jun. 2017, 7 pages.

[15] K. Ji, G. Tang, H. Pang, and J. Yang, "Impedance modeling and analysis of MMC-HVDC for offshore wind farm integration," IEEE Trans. Power Deliv., vol. 35, no. 3, pp. 1488-1501, Jun. 2020.

[16] M. K. Zadeh, M. Amin, J. A. Suul, M. Molinas, and O. B. Fosso, "Smallsignal stability study of the Cigré DC grid test system with analysis of participation factors and parameter sensitivity of oscillatory modes," in Proc. PSCC, Wroclaw, Poland, Aug. 2014, 8 pages.

[17] G. Pinares and M. Bongiorno, "Modeling and analysis of VSC-based HVDC systems for DC network stability studies," IEEE Trans. Power Deliv., vol. 31, no. 2, pp. 848-856, Apr. 2016.

[18] K. Ji, G. Tang, J. Yang, Y. Li, and D. Liu, "Harmonic stability analysis of MMC-based DC system using DC impedance model," IEEE J. Emerg. Sel. Top. Power Electron., vol. 8, no. 2, pp. 1152-1163, Jun. 2020

[19] S. D. Tavakoli, E. Prieto-Araujo, E. Sánchez-Sánchez, and O. GomisBellmunt, "Interaction assessment and stability analysis of the MMCbased VSC-HVDC link," Energies, vol. 13, no. 2075, pp. 1-19, Apr. 2020.

[20] G. Pinares and M. Bongiorno, "Methodology for the analysis of dcnetwork resonance-related instabilities in voltage-source converter-based multi-terminal HVDC systems," IET Gener. Transm. Distrib., vol. 12, no. 1 , pp. $170-177,2017$.

[21] A. J. Agbemuko, J. L. Domínguez-García, E. Prieto-Araujo, and O. Gomis-Bellmunt, "Dynamic modelling and interaction analysis of multi-terminal VSC-HVDC grids through an impedance-based approach," Int. J. Electr. Power Energy Syst., vol. 113, pp. 874-887, Jun. 2019.

[22] T. Li, A. M. Gole, and C. Zhao, "Harmonic instability in MMC-HVDC converters resulting from internal dynamics," IEEE Trans. Power Deliv., vol. 31 , no. 4, pp. $1738-1747,2016$

[23] R. Middlebrook, "Input filter considerations in design and application of switching regulators," in Proc. IEEE IAS Annual Meeting, Chicago, USA, Oct. 1976, pp. 366-382.

[24] M. Amin and M. Molinas, "Small-signal stability assessment of power electronics based power systems: A discussion of impedance- and eigenvalue-based methods," IEEE Trans. Ind. Appl., vol. 53, no. 5, pp. 5014-5030, Sep. 2017.

[25] C. Wang, L. Xiao, H. Jiang, and T. Cai, "Analysis and compensation of the system time delay in an MMC system," IEEE Trans. Power Electron., vol. 33, no. 11, pp. 9923-9936, Nov. 2018. 
[26] G. Stamatiou, M. Beza, M. Bongiorno, and L. Harnefors, "Analytical derivation of the DC-side input admittance of the direct-voltage controlled modular multilevel converter," IET Gener. Transm. Distrib., vol. 11, no. 16, pp. 4018-4030, Nov. 2017.

[27] G. N. Bathurst, N. R. Watson, and J. Arrillaga, "Modeling of bipolar HVdc links in the harmonic domain," IEEE Trans. Power Deliv., vol. 15, no. 3, pp. 1034-1038, Jul. 2000.

[28] J. R. Marti, L. Marti, and H. W. Dommel, "Transmission line models for steady-state and transients analysis," in Proc. IEEE/NTUA Athens Power Tech Conf., Athens, Greece, Sep. 1993, 7 pages.

[29] W. Leterme, S. P. Azad, and D. Van Hertem, "HVDC grid protection algorithm design in phase and modal domains," IET Renew. Power Gener, vol. 12, no. 13, pp. 1538-1546, May 2018.

[30] J. A. Martinez-Velasco, Power system transients - Parameter determination. Taylor \& Francis Group, New York, 2010.

[31] G. Stamatiou, "Analysis of VSC-based HVDC systems," Ph.D. dissertation, Chalmers University of Technology, 2016.

[32] J. Peralta, H. Saad, S. Dennetière, J. Mahseredjian, and S. Nguefeu, "Detailed and averaged models for a 401-level MMC-HVDC system," IEEE Trans. Power Deliv., vol. 27, no. 3, pp. 1501-1508, Jul. 2012.

[33] J. Khazaei, M. Beza, and M. Bongiorno, "Impedance analysis of modular multi-level converters connected to weak AC grids," IEEE Trans. Power Syst., vol. 33, no. 4, pp. 4015-4025, Jul. 2018.

[34] T. L. Heath, "Modular multilevel converter hardware and simulation comparison," Ph.D. dissertation, University of Manchester, 2019.

[35] Y. Wang, B. Zhang, and X. Fan, "The overhead transmission line protection scheme for the voltage-source converter-based HVDC grids," J. Eng., vol. 2019, no. 16, pp. 674-679, 2019.

[36] J. J. LaForest, L. E. Zaffanella, and M. G. Comber, Transmission line reference book - $345 \mathrm{kV}$ and above, 2nd ed. Palo Alto, US: Electric Power Research Institute, 1982.

[37] R. Dantas, J. Liang, C. E. Ugalde-Loo, A. Adamczyk, C. Barker, and R. Whitehouse, "Progressive fault isolation and grid restoration strategy for MTDC networks," IEEE Trans. Power Deliv., vol. 33, no. 2, pp. 909-918, Apr. 2018.

[38] K. Tahata, S. El Oukaili, K. Kamei, D. Yoshida, Y. Kono, R. Yamamoto, and H. Ito, "HVDC circuit breakers for HVDC grid applications," in Proc. IET ACDC 2015, Birmingham, UK, 2015, 9 pages.

[39] A. Riccobono and E. Santi, "Comprehensive review of stability criteria for DC power distribution systems," IEEE Trans. Ind. Appl., vol. 50, no. 5, pp. 3525-3535, Oct. 2014

[40] J. Beerten, S. D'Arco, and J. A. Suul, "Identification and small-signal analysis of interaction modes in VSC MTDC Systems," IEEE Trans. Power Deliv., vol. 31, no. 2, pp. 888-897, Apr. 2016.

[41] W. Wang, M. Barnes, O. Marjanovic, and O. Cwikowski, "Impact of DC breaker systems on multiterminal VSC-HVDC stability," IEEE Trans. Power Deliv., vol. 31, no. 2, pp. 769-779, Apr. 2016.

[42] H. Saad, Y. Fillion, S. Deschanvres, Y. Vernay, and S. Dennetière, "On resonances and harmonics in HVDC-MMC station connected to AC grid," IEEE Trans. Power Deliv., vol. 32, no. 3, pp. 1565-1573, Jun. 2017.

Thomas Roose (SM'18) received the M.Eng. and M.Sc. degrees in electrical engineering from the University of Leuven (KU Leuven), Belgium, in 2015 and 2018, respectively. He is currently pursuing his Ph.D. degree on stability analysis of dc power systems at KU Leuven and EnergyVille. His research interests include converter-related interactions, modular multilevel converters, impedance-based stability analysis, VSC-HVDC and bipolar LVDC systems.
Mohammad M. Alam received his B.Tech. degree in electrical engineering from the Aligarh Muslim University, India, M.Tech. degree in power systems from the Indian Institute of Technology Delhi, India and a Ph.D. degree in electrical engineering from the University of Porto, Portugal in 2009, 2012 and 2018, respectively. Currently, he is a researcher at VITO and Energyville. His research interests include dc networks, battery system and renewable energy analysis and control.

In 2010, he was an Erasmus Mundus scholar at the Institut Nationale de Polytechnique (INP), Grenoble for 1 year. From 2012 to 2013, he was working as an R\&D engineer at GE Energy, India. Later on, he was a Marie Curie scientific scholar from November 2013 to November 2016 at the university of Porto, Portugal. He joined as a post-doctoral researcher at KU Leuven from July 2017 to August 2018.

Dr. Mohammad Meraj Alam was also a visiting researcher at the Cardiff University, Wales from May 2015 to July 2015, at Efacec sistemas from February 2016 to April 2016 and at KU Leuven from October 2016 to November 2016. His initiatives in solar plus battery storage systems are well recognized in KIC ClimateLaunchpad 2017, EU PARSEC call 2019 and everis Belgian awards 2020 .

Jef Beerten (S'07, M'13, SM'19) received the M.Sc. degree in electrical engineering and a Ph.D. in electrical engineering from the University of Leuven (KU Leuven), Belgium, in 2008 and 2013, respectively. Currently, he is an assistant professor with KU Leuven and EnergyVille. His research interests include future power system dynamics, modeling, and control.

In 2011, he was a visiting researcher at the Royal Institute of Technology (KTH), Stockholm, Sweden, for three months. From April 2014 until March 2015, he was a visiting postdoctoral researcher at the Norwegian University of Science and Technology (NTNU), Trondheim, Norway.

Dr. Beerten was the first winner of the ABB Research Award in Honor of Hubertus von Gruenberg in 2016 and received the KBVE/SRBE Robert Sinave Award and the Prix Paul Caseau from the Institut de France - EDF Foundation for his Ph.D. thesis on modeling and control of DC grids. Dr. Beerten is an active member of both the IEEE and CIGRE.
Aleksandra Lekić (M'18) received the B.S., M.S., and Ph.D. degrees in electrical engineering from the School of Electrical Engineering, University of Belgrade, Serbia, in 2012, 2013, and 2017, respectively. Between 2012 and 2018 she has been a Teaching Assistant with the School of Electrical Engineering, University of Belgrade, and an Assistant Professor from 2018 to 2019. In 2019 she worked as a Postdoctoral Researcher at the Department of Electrical Engineering ESAT - ELECTA, KU Leuven and in the Institute EnergyVille, Genk, Belgium. From January 2020, Aleksandra works as an Assistant Professor at TU Delft, Faculty of Electrical Engineering, Mathematics and Computer Science in the group Intelligent Electrical Power Grids. 